\title{
Toxicant-Induced Fecundity Compensation: A Model of Population Responses ${ }^{1}$
}

\author{
A. L JENSEN ${ }^{2}$ \\ School of Natural Resources \\ University of Michigan \\ Ann Arbor, Michigan 48109

\section{J. S. MARSHALL \\ Ecological Sciences Section \\ Radiological and Environmental Research Division \\ Argonne National Laboratory} \\ Argonne, Illinois 60439
}

ABSTRACT / A mathematical model widely applied in population studies and in assessment of the impact of exploitation on fish populations was applied to assess cadmium toxicity in laboratory populations of Daphnia galeata mendotae. Over a range of toxicant concentrations, the birth rate of the population increased to balance the death rate and the population compensated for the increased mortality. The model describes the relation between toxicant concentration, toxicant-induced mortality, and equilibrium population size. Compensation for increased mortality is described in terms of the decrease in population size necessary to produce an increase in the birth rate that will balance the increased death rate. The relative capacity of different aquatic organisms to compensate for toxicant-induced mortality is examined and a relation between compensatory capacity and the innate capacity for increase is developed.
Populations subjected to mortality induced by exposure to toxicants compensate to offset this mortality so that its impact on populations will not be as severe as observations of individuals indicate. Compensation provides a margin of safety, but its results are gradual and more difficult to detect. In this study a mathematical mode' is developed and applied to describe the toxic impaci. of cadmium on laboratory populations of Daphnia and the responses of the populations to this impact. The model is applied to examine the relations among the levels of stress, population size, birth rate, and death rate.

\section{The Model}

A mortality equation for some concentration of a toxicant that increases the death rate is

$$
d D / d t=Z N
$$

where $D$ is the number of toxicant-induced deaths, $N$ is the population size, and $Z$ is the toxicant-induced mortality rate per individual. The toxicant-induced mortality rate is a function of toxicant concentration; the simplest relation is

$$
Z=h\left(C-C_{0}\right)
$$

KEY WORDS Toxicant-induced mortality; Environmental modeling; Fecundity compensation

\footnotetext{
${ }^{1}$ Work performed under the auspices of the United States Environmental Protection Agency.

${ }^{2}$ Work completed while on sabbatical leave at Argonne National Laboratory.
}

for $C \geq C_{0}$, where $h$ is the toxicant-induced mortality coefficient (time $\cdot \mu \mathrm{g} / \mathrm{L})^{-1}, C$ is the toxicant concentration in $\mu \mathrm{g} / \mathrm{L}$, and $C_{0}$ is the threshold toxicant concentration (which might be zero).

To apply the toxicant mortality equation, an equation must be developed for change in population size. The capacity of a population to compensate for increased mortality is a function of population size with the compensatory capacity low at both low and high population sizes and a maximum at some intermediate population size. Application of a parabola to describe the relation between the capacity to increase and population size, which is the simplest approach, gives the model

$$
\begin{aligned}
& d D / d t=h\left(C-C_{0}\right) N \\
& d N / d t=r N-r N^{2} / K-h\left(C-C_{0}\right) N
\end{aligned}
$$

where the new symbols are $r$ is the innate capacity for the population to increase (time) $)^{-1}$, and $K$ which is the environmental carrying capacity in numbers. The above population growth equation is the logistic equation. The toxicity of a chemical under a particular set of conditions and the sensitivity of the individuals tested determines the value of the parameter $h$. The capacity of the population to respond to the toxic impact determines the value of the parameter $r$.

Equations (3) and (4) indicate that at every toxicant concentration such that $C<C_{0}+r / h$, the population will approach an equilibrium population of size

$$
N_{e}=K-h K\left(C-C_{0}\right) / r .
$$

Substitution of (5) into (4) gives the equilibrium relation between toxicant-induced mortality and toxicant con- 
centration as

$$
d D / d t=h K\left(C-C_{0}\right)-K h^{2}\left(C-C_{0}\right)^{2} / r
$$

for $C \geq C_{0}$. As the toxicant concentration increases above the threshold, the toxicant-induced death rate, $d D / d t$, increases to a maximum at $C=C_{0}+r / 2 h$ and then begins to decrease.

The capacity of a population to compensate for toxicant-induced mortality can be described by formulating the decrease in population size in terms of the toxicant concentration or toxicant-induced mortality per individual. A measure of compensatory capacity is the change in population size resulting from an increase in mortality. At equilibrium for any toxicant concentration $C \geq C_{0}$ and $C<C_{0}+r / h$, the decrease in population size, $\Delta N=K-N_{e}$, is given as

$$
\Delta N=h K\left(C-C_{0}\right) / r
$$

The proportion reduction in the size of the population below the carrying capacity, $\triangle P$, resulting from a toxicant concentration $C$ is

$$
\Delta P=h\left(C-C_{0}\right) / r .
$$

\section{Results and Discussion}

Marshall (1978) determined the impact of cadmium on laboratory populations of Daphnia galeata mendotae (Table 1). Four separate populations were studied at each of 8 different cadmium concentrations, and there also were 8 control populations. Several population attributes were measured, including the birth rates, death rates, and abundances. To fit the model to the cadmium toxicity data, the toxicant-induced death rate for each cadmium concentration was estimated as $d D / d t=d N-d_{c} N_{c}$ where $d_{c}$ and $N_{c}$ are the death rate and population size of the controls. No threshold for cadmium toxicity was observed (Marshall 1978) so $C_{0}$ was set equal to zero. The method of least squares was applied with (3) to estimate $h$ as 0.018 (day $\mu \mathrm{g} / \mathrm{L})^{-1}$. The coefficient of determination was $R^{2}=0.89$. The parameters $r$ and $K$ of (4) were estimated by least squares as $r=0.29$ day $^{-1}$ and $K=147$ individuals $\left(R^{2}=0.94\right)$. The model fits the observations well and describes much of the variation in toxicantinduced mortality. Frank and others (1957) and Marshall (1962) estimated $r$ for Daphnia pulex as 0.30 day $^{-1}$ and 0.32 day $^{-1}$, respectively.
Table 1. Relation between cadmium concentration, birth rate, death rate, population size, and toxicant-induced mortality rate in Daphnia galeata mendotae.

\begin{tabular}{ccccc}
\hline $\mathrm{Cd}(\mathrm{g} / \mathrm{L})$ & $\bar{b}$ & $\bar{d}$ & $\bar{N}$ & $\begin{array}{c}\text { Toxicant-induced } \\
\text { mortality rate }\end{array}$ \\
\hline 1 & 0.087 & 0.081 & 149 & 0 \\
1 & 0.102 & 0.092 & 142 & 1.56 \\
2 & 0.102 & 0.094 & 142 & 1.85 \\
4 & 0.149 & 0.138 & 114 & 6.04 \\
5 & 0.166 & 0.168 & 90 & 7.83 \\
8 & 0.326 & 0.306 & 62 & 13.95 \\
10 & 0.242 & 0.242 & 48 & 7.73 \\
15 & 0.376 & 0.372 & 23 & 6.69 \\
\hline
\end{tabular}

As the toxicant concentration increases, the toxicant induced death rate (6) increases to a maximum at $C=$ $r / 2 h=8.05 \mu \mathrm{g} / \mathrm{L}$ and then it begins to decrease (Figure 1). On the average, the populations will become extinct when $C \geq 16 \mu \mathrm{g} / \mathrm{L}$, but in the laboratory random fluctuations in population size resulted in extinction at somewhat higher and lower concentrations. Exposure of Daphnia populations to toxic concentrations of cadmium results in an increased death rate, but over a wide range of cadmium concentrations the birth rate increases to balance the increase in the death rate and compensates for the toxicant-induced mortality. Under toxic stress population size decreases, growth of individuals increases, more young are produced per female, the proportion of oviparious females increases substantially, and the birth rate increases. Similar factors have been observed operating in fish populations responding to exploitation (McFadden 1977, Jensen 1971) and to heavy metal toxic stress (McFarlane and Franzin 1978).

If individual daphnids are tested in separate containers, increased cadmium concentrations cause both an increase in the death rate and a decrease in the production of young (Bertram and Hart 1979). This same result occurs with exposure of daphnids to chronic radiation stress (Marshall 1962, 1966). Compensatory responses are not observed when individuals are tested separately.

The experiment determined the response of Daphnia populations to cadmium under one set of environmental conditions, but the response is a function of the innate capacity for increase which is a function of environmental condition. For example, the innate capacity for increase of the grain beetle (Calandra aryzae) varied from zero under cool dry conditions to nearly 0.80 under 


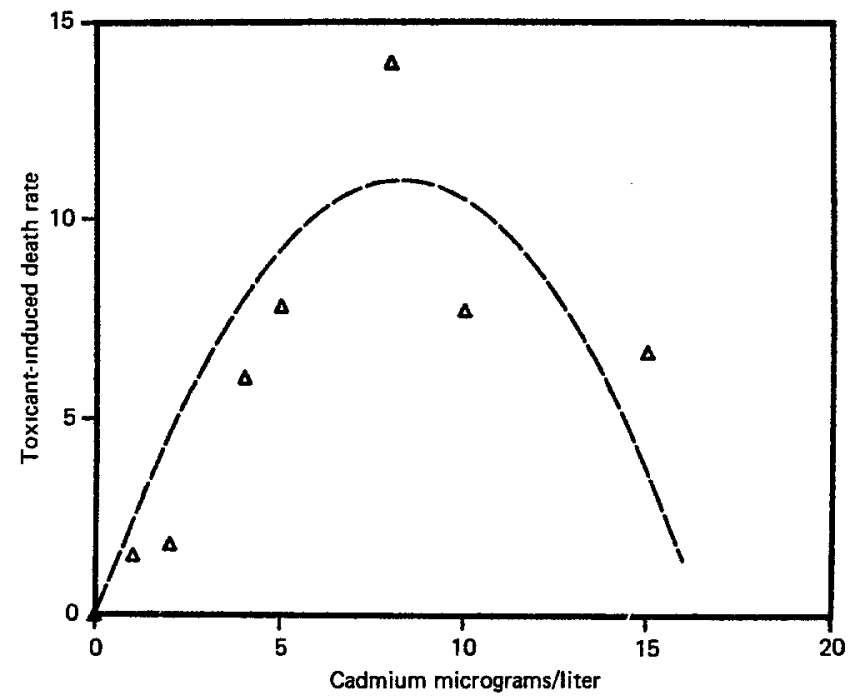

Figure 1. Observed and predicted (parabola) relations between cadmium concentrations and toxicant-induced mortality.

warm moist conditions (Birch 1953). For cladocerans the reported values of $r$ range from 0.2 day $^{-1}$ to 0.6 day $^{-1}$ (Allan 1976), and application of (8) using $r$ values of 0.2 day $^{-1}$ and 0.6 day $^{-1}$ give the range of the impact of cadmium on cladoceran population size (Figure 2) assuming $h$ remains constant. An increase in the value of $r$ from 0.29 to 0.60 reduces the impact on population size by $50 \%$, and a decrease in $r$ from 0.29 to 0.20 increases the impact by $33 \%$. It is probable that the observed $r$ value of 0.29 day $^{-1}$ is higher than would occur in many natural Daphnia populations and the impact on natural populations could be substantially higher than that observed in the laboratory.

Smith (1954), Pianka (1970), and Fenchel (1976) summarized $r$ values for many species and the observed values indicate the relative compensatory capacities. For Escherichia coli the value of $r$ is about $60 \mathrm{day}^{-1}$ and for several other species of bacteria, $r$ ranges from 35 to 55 day $^{-1}$. For protozoans, $r$ ranges from $0.60 \mathrm{day}^{-1}$ to 7.5 day $^{-1}$. Rotifers have $r$ values from 0.2 to 1.5 day $^{-1}$ and copepods from 0.1 to $0.4 \mathrm{day}^{-1}$. For pond snails (Physa gyrina) $r$ was estimated as $0.027 \mathrm{day}^{-1}$. Many estimates of $r$ are available for fishes. In fishery stock assessment, a biomass equation for population size is applied instead of an equation for numbers, but the innate capacity for increase determined using biomass is comparable to that determined using numbers (Jensen 1972). For lake whitefish (Coregonus clupeaformis) in the Great Lakes, $r$ varies from 0.22 year $^{-1}$ to 0.50 year $^{-1}$ (Jensen 1976), and

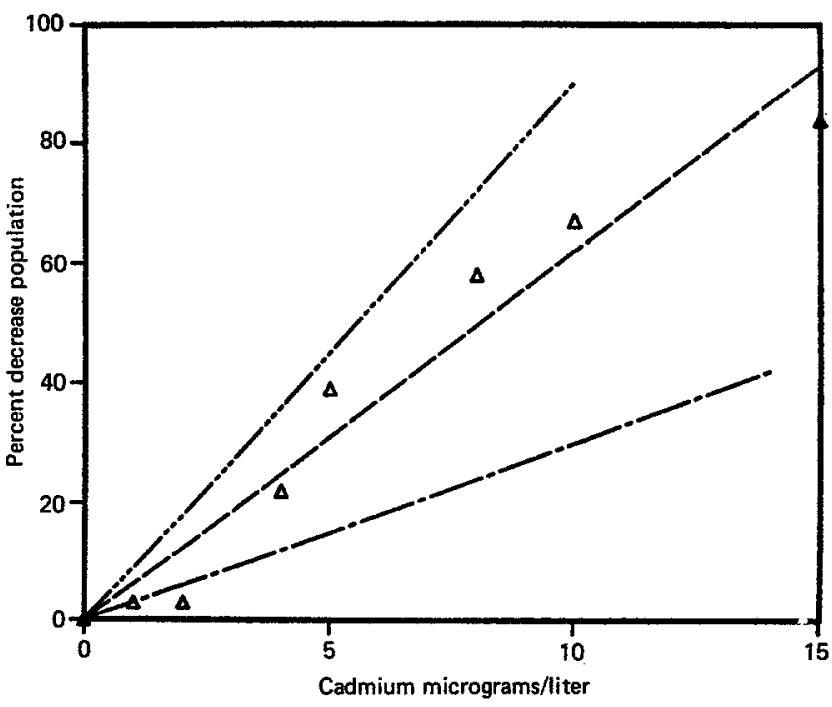

Figure 2. Observed relation (triangles) and predicted relations between cadmium concentrations and percent decrease in population size for $r$ values of 0.20 (top line), 0.29 (middle line), and 0.60 (bottom line).

for lake trout (Salvelinus namaycush) $r$ is 0.48 year $^{-1}$ (Jensen 1978). The capacity for compensation is in decreasing order: bacteria $>$ protozoa $>$ rotifera $>$ cladocera $>$ copepods $>$ bottom fauna $>$ fish.

The observed values of $r$ for Daphnia may be of ecological significance. The impact of toxicant-induced mortality on the Daphnia populations at three cadmium concentrations for a range of $r$ values is shown in Figure 3. Values of $r$ higher than 0.60 day $^{-1}$ have not been reported for cladocerans, and the higher values are shown only to illustrate the impact of $r$ on the decrease in population size for a given toxicant-induced mortality. At a cadmium concentration of $2 \mu \mathrm{g} / \mathrm{L}$, which produces a $60 \%$ increase in mortality, the reduction in population size is small for large values of $r$ and the reduction in population size does not increase much as $r$ decreases to $0.5 \mathrm{day}^{-1}$. For $r$ values decreasing between 0.5 day $^{-1}$ and 0.3 day $^{-1}$, the decrease in population size is more rapid and for $r$ values below 0.30 day $^{-1}$, population size decreases rapidly as $r$ decreases. High values of $r$ increase the resource demands of Daphnia but provide little increased capacity to compensate for environmental changes that increase mortality by a small amount. However, if $r$ is much below the observed value of 0.30 day $^{-1}$, environmental changes that produce small increases in mortality could have a large impact on population size. The observed innate capacity for increase enables Daphnia populations to com- 


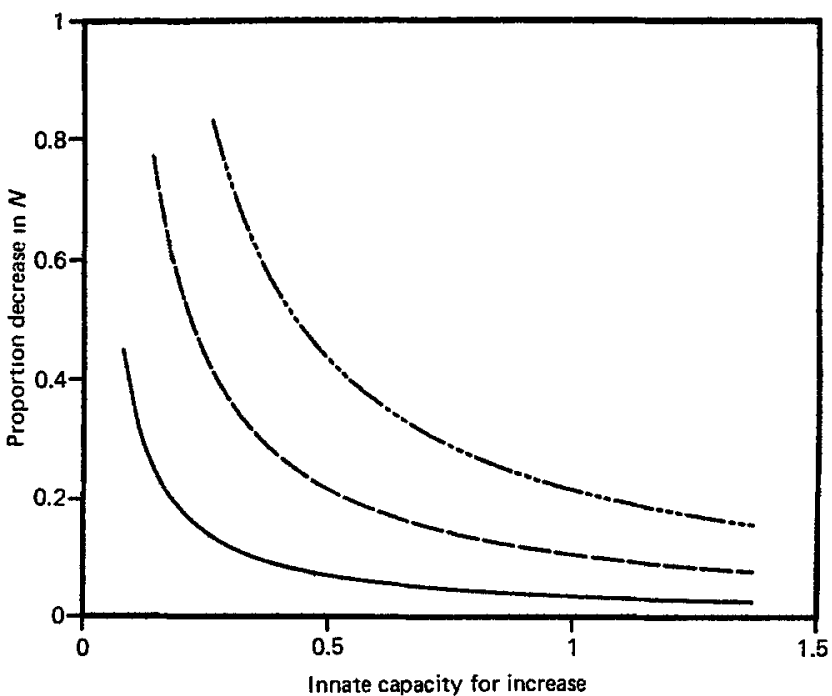

Figure 3. Relation between proportion decrease in population size and the innate capacity for increase for three different cadmium concentrations. From the top down: $12 \mu \mathrm{g} / \mathrm{L}, 6 \mu \mathrm{g} / \mathrm{L}$, and $2 \mu \mathrm{g} / \mathrm{L}$.

pensate for smaller environmental changes without a large decrease in population size, and these small perturbations occur most frequently.

The model proposed here for description of compensatory capacity is the simplest reasonable model, but many modifications of the logistic equation have been proposed. Pella and Tomlinson (1969) developed a more flexible function; Marchesseault and others (1976) developed a model with a reproductive time lag; Ricker (1958) and Beddington and May (1977) developed stochastic models; and Clark (1973) and Phelp (1957) developed modifications in which extinction occurs if the population size falls below a critical size. In some situations such modifications may be necessary, but the simple logistic model adequately describes the Daphnia data.

Populations have a capacity to compensate for environmental impacts, but this does not lessen the significance of impacts nor ameliorate them. A decrease in population size is necessary to produce an increase in the birth rate to offset toxicant-induced mortality, and a decrease in population size may result in a decrease in biological production. A reduction in zooplankton population density may increase the required effort per unit of catch of planktivorous fishes, and reduction in size of plankton will reduce the energy intake per unit of effort. Sizeselective planktivores may be especially vulnerable to this impact. Another important ecological impact of toxicity is the increase in the birth rate that reduces the population's capacity to respond to normal environmental stress.

\section{Acknowledgment}

W. G. Franzin, D. P. Scott, and B. deMarch of the Canadian Freshwater Institute, Winnipeg, Manitoba, Canada reviewed an early version of this manuscript and gave many helpful suggestions.

\section{Literature Cited}

Allan, J. D. 1976. Life history patterns in zooplankton. American Naturalist. 110:165-180.

Beddington, J. R., and R. M. May 1977. Harvesting natural populations in a randomly fluctuating environment. Science 197:463-465.

Bertram, P. E., and B. A. Hart. 1979. Longevity and reproduction Daphnia pulex (DeGeer) exposed to cadmium-contaminated food or water. Environ. Pollut. 19:295-305.

Birch, L. C. 1953. Experimental background to the study of the distribution and abundance of insects. 1 . The influence of temperature, moisture, and food on the innate capacity for increase of three grain beetles. Ecology 34:668-671.

Clark, C. W. 1973. The economics of overexploitation. Science 181:630-634.

Fenchel, T. 1974. Intrinsic rate of natural increase: The relationship with body size. Oecologia. 14:317-326.

Frank, P. W., C. D. Boll, and R. W. Kelly, 1957. Vital statistics of laboratory cultures of Daphnia pulex DeGeer as related to density. Physiol. Zool. 30:287-305.

Jensen, A. L. 1971. Response of brook trout (Salvelinus fontinalis) populations to a fishery. J. Fish. Res. Board Can. 28:458460.

Jensen, A. L. 1972. Population biomass, number of individuals, average individual weight, and the linear surplus production model. J. Fish. Res. Board Can. 29:1651-1655.

Jensen, A. L. 1976. Assessment of the United States lake whitefish fisheries of Lake Superior, Lake Michigan, and Lake Huron. J. Fish. Res. Board Can. 33:747-759.

Jensen, A. L. 1978. Assessment of the lake trout fishery in Lake Superior: 1929-1950. Trans. Amer. Fish. Soc. 107:543-549.

Marchesseault, G. D., S. B. Saila, and W. J. Palm. 1976. Delayed recruitment models and their application to American lobster (Homarus americanus) fishery. J. Fish. Res. Board Can. 33:17791787.

Marshall, J. S. 1962. The effects of continuous gamma radiation on the intrinsic rate of natural increase of Daphnia pulex. Ecology 43:598-607.

Marshall, J. S. 1966. Population dynamics of Daphnia pulex as modified by chronic radiation stress. Ecology 47:561-571. 
Marshall, J. S. 1978. Population dynamics of Daphnia galeata mendotae as modified by chronic cadmium stress. J. Fish. Res. Board Can. 35:461-469.

McFadden, J. T. 1977. An argument supporting the reality of compensation in fish populations and a plea to let them exercise it. In W. Van Winkle (ed.). Assessing the effects of powerplant-induced mortality on fish populations. Pergamon Press, New York, NY.

McFarlane, G. A., and W. G. Franzin, 1978. Elevated heavy metals: A stress on a population of white suckers (Catostomus commersoni) in Harneli Lake, Saskatchewan. J. Fish. Res. Board Can. 35:963-970.

Pella, J. J., and P. K. Tomlinson. 1969. A generalized stock production model. Inter. Amer. Trop. Tuna Comm. Bull. 13:419496.

Phelp, J. R. 1957. Sociality and sparse populations. Ecology 38:107-1.11.

Pianka, E. R. 1974. Evolutionary ecology, Chiron Press. New York.

Ricker, W. E. 1958. Maximum sustained yields from fluctuating environments and mixed stocks. J. Fish. Res. Board Can. 15:991-1006.

Smith, F. E. 1954. Quantitative aspects of population growth. Pages 274-194.in E. Boell (ed.). Dynamics of growth processes. Princeton University Press, Princeton, NJ. 